\title{
Development of a single-pass detailed damage mapping application
}

\author{
D Cumming-Potvin Australian Centre for Geomechanics, The University of Western Australia, Australia \\ Y Potvin Australian Centre for Geomechanics, The University of Western Australia, Australia \\ J Wesseloo Australian Centre for Geomechanics, The University of Western Australia, Australia \\ P Harris Australian Centre for Geomechanics, The University of Western Australia, Australia \\ C Ho Australian Centre for Geomechanics, The University of Western Australia, Australia \\ M Heinsen Egan Australian Centre for Geomechanics, The University of Western Australia, Australia
}

\begin{abstract}
High-quality data is crucial in back-analysis of rockburst data and the development of empirical design methods. Data collection and reporting is currently predominantly a manual process (creating a two-pass system) with limited organisation or standardisation. To facilitate the collection, management and analysis of high-quality rockburst damage data, a damage mapping application was developed. This application is designed for offline use with tablet devices, creating a single-pass system.

The data captured by the application includes information on location, rock mass conditions, installed ground support and corrosion, falls of ground, damage and photos.

The application was designed with four goals in mind: consistency, speed, comprehensiveness and simplicity. To achieve these goals, a number of custom-made widgets were employed for optimal data input. Once input is complete, the data is synchronised to a server on the mine network and is then available for further analysis with an mXrap app.
\end{abstract}

Keywords: damage mapping, rockburst, ground support, tablet

\section{Introduction}

The standardisation of the rockburst data being collected is critical to the development of future empirical design methods. The Australian Centre for Geomechanics' Ground Support Systems Optimisation Phase 2 (GSSO2) project, which has a subproject that focuses on empirical design methods, required high-quality data regarding rockbursts in a number of mines.

Observations of practices at mines in Australia, Canada and Sweden indicate a number of problems with current rockburst data collection methods. The majority of mines currently collect damage mapping data by hand (i.e. using a pen and paper). These results then need to be digitised, creating a two-step process. This process is cumbersome and time-consuming and creates additional opportunities for errors to enter the database.

The databases created are often overly simplified and/or poorly structured, limiting their value in back-analysis. They often consist of a single spreadsheet, with one line per damage location. This creates a single-level database, and damage on different parts of the profile (shoulders, backs, etc.) cannot be differentiated. This structure requires general information that may apply to many locations to be repeated, such as the date of observation. Important quantitative information may be buried in notes that cannot easily be accessed and statistically analysed. It is also common for mines not to have a rockburst database and to rely simply on a folder with reports in PDF format. This situation makes any quantitative back-analysis incredibly difficult. 
Rockburst occurrence is relatively rare; therefore, collating data from multiple mines improves the quality of back-analysis and the design methods resulting from it. However, the information collected may vary significantly from mine to mine, limiting the ability to collate the data. Additionally, mines often do not have standards for data collection, and the data collected is therefore not always consistent, jeopardising the validity of any empirical analysis.

Many databases include seismic monitoring data alongside damage data. This may result in the damage observations being polluted by the seismic event data as the collector tries to make the two types of data match (i.e. trying to a fit a narrative). It may also affect the conclusions made about the relationship between seismic events and damage, as the person doing the analysis may have come to a decision during data collection.

Another problem commonly encountered is that the damage scales typically used do not separate the extent of damage (i.e. length or area affected) from the severity. The two concepts are separate and should be discretely accounted for in damage mapping, otherwise the scale will be severely limited in its ability to represent damage intensity. For example, a 200 tonne rockburst in a $5 \mathrm{~m}$ long section of drive is very different in severity to a 200 tonne rockburst over a length of $100 \mathrm{~m}$, but they may be categorised with the same damage level. This issue is discussed in detail by Duan et al. (2015).

The results of damage mapping are often not well organised and may be divorced from photographs of the damage. This results in a value loss, where the photographs have no spatial context.

Due to the of the lack of quality databases in the industry, a new system needed to be developed to enable mines to quickly and efficiently collect this high-quality data in a standardised manner. This was achieved through a web-based tablet application. The application was designed to be thorough, enabling collection of data on all the fields necessary to conduct a complete back-analysis. The application also needed to be optimised for rapid data collection to ensure practical use underground.

\section{Database structure}

The database was structured with three primary levels: report, track and point. These levels were necessary to ensure the data is captured to the relevant degree of accuracy.

\subsection{Report level}

The report level contains the basic information pertaining to the entire damage mapping report (i.e. observation date and time, person making the observations).

\section{$2.2 \quad$ Track level}

The tracks are the individual locations of damage underground. They are 5-10 m lengths of excavation, with a particular geometry (e.g. drive/drift, three-way intersection, four-way intersection). The tracks are persistent (i.e. the same track can be used for multiple reports), meaning that damage can be tracked over time. The 5-10 m length was chosen for two main reasons:

- It allows sufficient granularity for the tracking of damage over time.

- It helps to separate the extent of damage from the severity.

Examples of tracks placed on a level plan are given in Figure 1. 

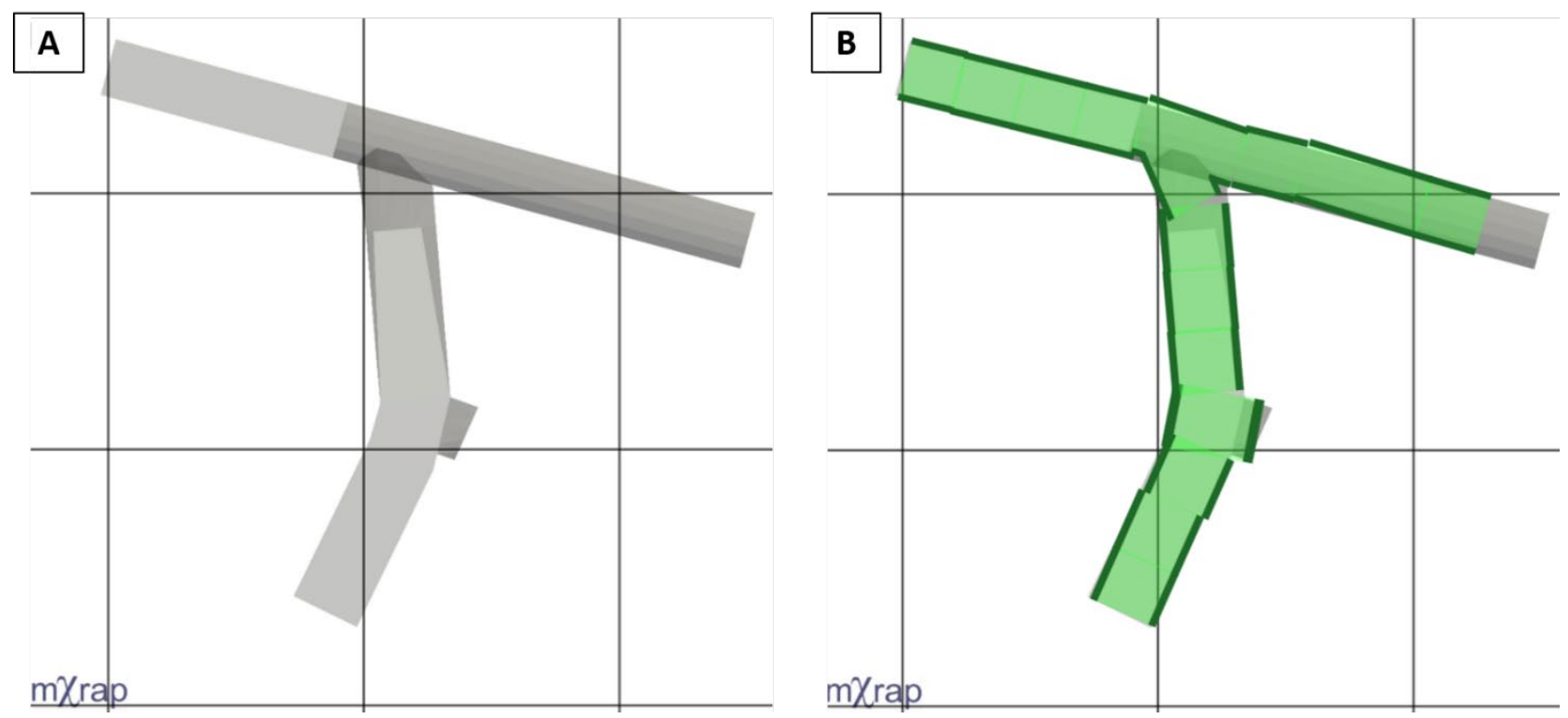

Figure 1 Level plan: (a) Before tracks have been placed; (b) After track placement

\subsection{Point level}

The points are the locations on the profile of each track. They consist of the backs, shoulder, wall, lower wall (i.e. below gradeline) and floor. Examples of the points are shown in Figure 2.

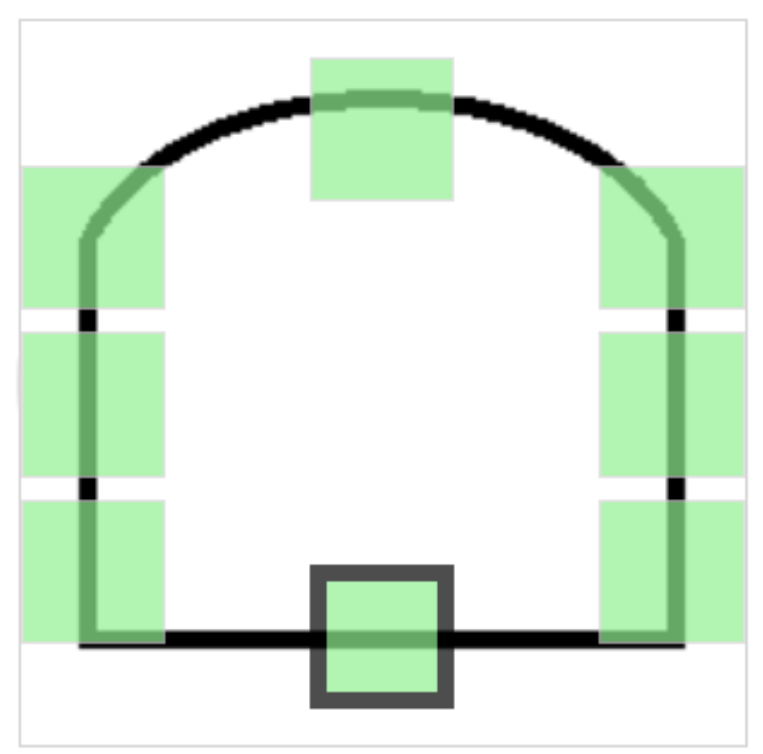

\section{Figure 2 Example of points on drive profile}

The points for intersections are based on the corners of the intersection for the shoulders, walls and lower walls, and on the centre of the intersection for the backs and floor. The picture of the intersection is oriented to match the track, and also includes an arrow. This allows the user to understand and record which corner of the intersection is being mapped, along with the location on the profile (backs, shoulder, etc.). For example, in Figure $3 a$, the user has selected the northeast shoulder of the intersection, and in Figure $3 \mathrm{~b}$, they have selected the southwest wall. 

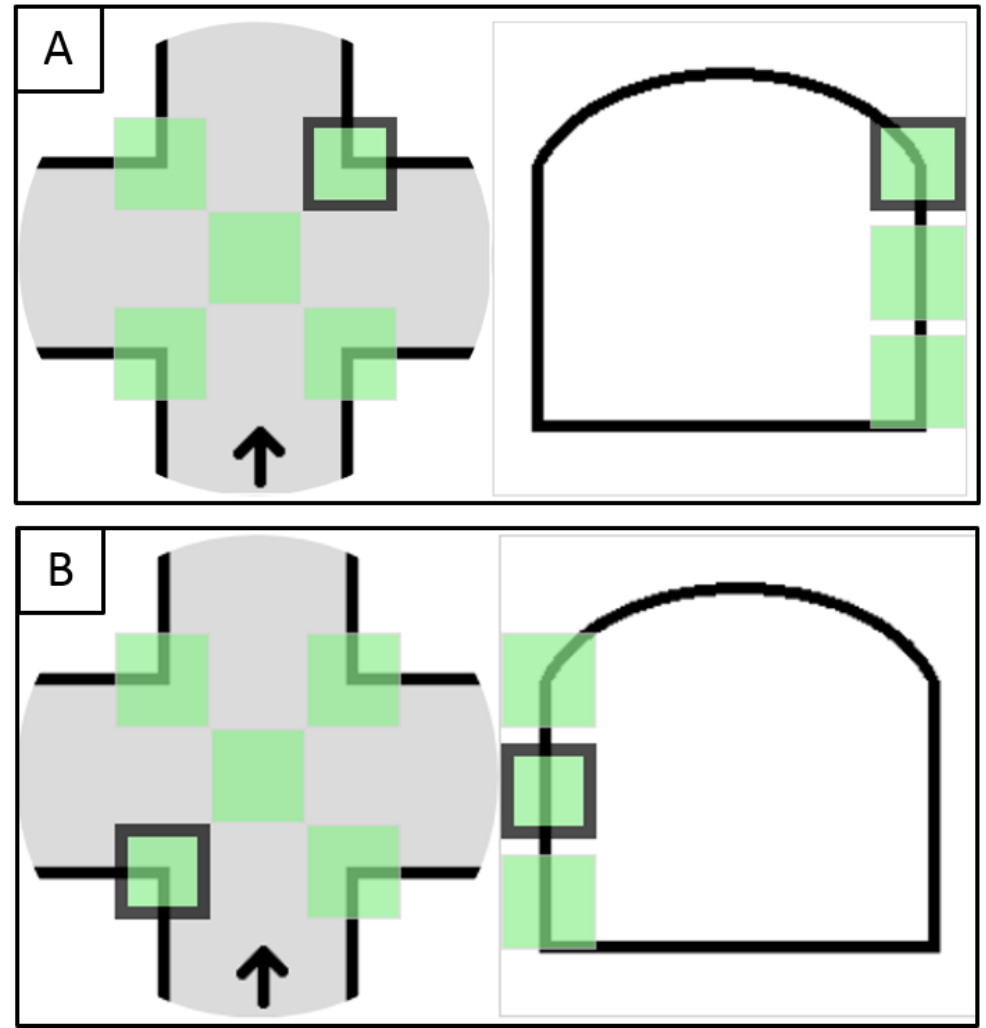

Figure 3 Example of intersection point selection for (a) Northeast shoulder; (b) Southwest wall

\section{Data to collect}

The most important factor to consider when designing a data collection system is the data that needs to be collected. When choosing the parameters to include, the following questions must be considered:

- What information is needed for quantitative back-analysis?

- What is required by regulators?

- What is important contextual information?

- What is practical to collect?

It is important to note that seismic monitoring data should not be collected using a damage mapping application. Observational data (such as damage mapping) should be kept distinct from measured data (such as seismic events). The two can be correlated later on; however, it is crucial not to pollute observational data with assumptions about the source of the damage.

\subsection{Basic information}

Some basic information for each damage mapping report needs to be captured. This includes:

- Date and time of observation.

- Person making the observation.

- Short summary of the observation.

For rockbursts, it is also important to capture the time since the last observation. This allows a period to be defined within which a damaging event could have occurred (instead of assuming that the damaging event was the most recent). Multiple observations of the same location as part of a routine ground-condition auditing process could also aid in establishing which damage was truly associated with a rockburst, which further supports the need for a systematic documentation process. 


\subsection{Location information}

Some basic information also needs to be captured for each location of damage underground (Table 1).

\section{Table 1 Location information}

\begin{tabular}{|c|c|}
\hline Field & Comment \\
\hline Damage co-ordinates & i.e. $X, Y, Z$ \\
\hline Name of location & e.g. Level 10, Oredrive 1 \\
\hline \multicolumn{2}{|l|}{ Excavation height } \\
\hline \multicolumn{2}{|l|}{ Excavation span } \\
\hline Excavation type & e.g. drive/drift, stope, orepass \\
\hline Excavation geometry & $\begin{array}{l}\text { Straight section of development, three-way intersection, four-way } \\
\text { intersection, etc. }\end{array}$ \\
\hline Drive orientation & \\
\hline
\end{tabular}

\subsection{Rock mass conditions}

The following rock mass conditions are important to capture for each damage location (Table 2).

Table 2 Rock mass condition information

\begin{tabular}{ll}
\hline Field & Comment \\
\hline Lithology & \\
Rock mass quality & i.e. Q', RMR, GSI \\
Foliation & Dip, dip direction \\
Major structures & Name (if known), dip direction, thickness, infill \\
Presence of water & \\
\hline
\end{tabular}

\subsection{Installed support}

Capturing the installed ground support is key to understanding the performance of support systems. It is particularly important to capture, as best as possible, the support as installed and not the planned support. Information that needs to be captured is given in Table 3.

Table 3 Ground support element information

\begin{tabular}{llll}
\hline Bolt & Mesh & Straps & Shotcrete \\
\hline Type of bolt & Type of mesh & Type of straps & $\begin{array}{l}\text { Type (plain, steel/synthetic } \\
\text { fibres) }\end{array}$ \\
Ring spacing & Spacing & Thickness \\
Bolt spacing & $\begin{array}{l}\text { Orientation (horizontally along drive or } \\
\text { vertical up wall) }\end{array}$ & \\
\hline
\end{tabular}

It is also important to capture where on the profile the support was installed. Support systems that are only installed shoulder-to-shoulder are significantly different from those that are installed floor-to-floor. Some support systems are also installed with support that is different in one side of the drive from the other. 
Additionally, it is important to capture the corrosion conditions as they can have a significant impact on support system capacity. Corrosion must be captured per element because the corrosion properties of different elements can vary significantly. This is illustrated in Figure 4, where the cable bolt has advanced corrosion whereas the split set is still in relatively good condition.

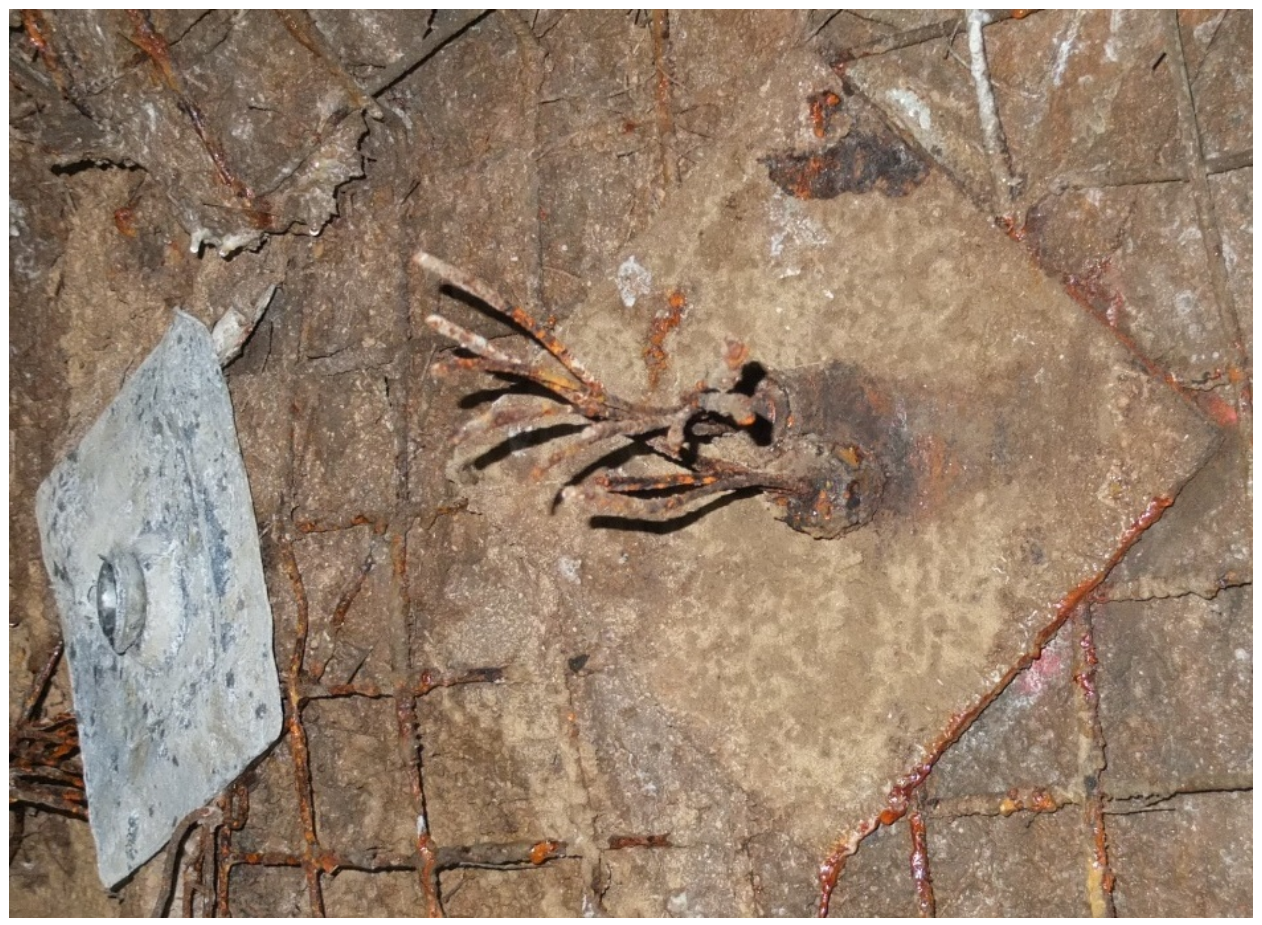

Figure 4 Example of different corrosion rates of ground support elements

\subsection{Damage}

Damage can be split into three categories: damage to the rock mass, damage to support and falls of ground. It is also important to include provision for the user to enter locations that did not experience damage, as these are important data points for back-analysis.

\subsubsection{Falls of ground}

Important fields to collect for falls of ground are given in Table 4.

Table 4 Falls of ground information

\begin{tabular}{|c|c|}
\hline Field & Comment \\
\hline Volumes/tonnes of failed material & Easier to collect as bulked volume or tonnes \\
\hline Fragmentation of the rock pile & Shape and size of fragmented material \\
\hline Material type & $\begin{array}{l}\text { Whether it was rock, or simply shotcrete that has been } \\
\text { dislodged or loosened }\end{array}$ \\
\hline $\begin{array}{l}\text { Where in the profile the fall of ground } \\
\text { came from }\end{array}$ & Backs, shoulders, walls, lower walls \\
\hline
\end{tabular}




\subsubsection{Rock mass damage}

If there is a fall of ground, it is important to capture the depth of failure and determine whether the failure is structurally bounded. If there is no fall of ground, the wall movement (essentially a measure of bulking) should be recorded.

Kaiser et al. (1995) proposed a rock mass damage scale (Figure 5). This scale is widely used within the industry and required for rockburst reporting by some jurisdictions and is therefore a practical benchmark value to capture.

\begin{tabular}{|c|l|l|}
\hline Damage level & General description & Rockmass / excavation damage \\
\hline R0 & Conditions unchanged & No new damage due to rockburst \\
\hline R1 & $\begin{array}{l}\text { Excavations } \\
\text { undamaged but first } \\
\text { signs of distress } \\
\text { detectable }\end{array}$ & $\begin{array}{l}\text { Rock shows fresh but minor, small fractures and cracks (possibly } \\
\text { behind 'loose') } \\
\text { Small shards of rock may have been displaced }\end{array}$ \\
\hline R2 & $\begin{array}{l}\text { Slight damage to } \\
\text { excavations } \\
\text { Only 'loose' displaced }\end{array}$ & $\begin{array}{l}\text { Slight sloughing from back and walls of unsupported excavations (only } \\
\text { 'loose' rock displaced, little freshly broken rock) } \\
\text { Small shards and a few chunks of rock displaced in supported } \\
\text { excavations (possibly retained by mesh) } \\
\text { Rockmass shows only minor new fracturing }\end{array}$ \\
\hline R3 & $\begin{array}{l}\text { Minor damage to } \\
\text { excavations } \\
\text { 'Loose' displaced and } \\
\text { new rock failure }\end{array}$ & $\begin{array}{l}\text { Unsupported drifts sustain damage with <200 kg of rock displaced } \\
\text { from either a fall of ground or due to newly generated fracturing of rock } \\
\text { (spalling) } \\
\text { In drifts supported with only rockbolts and mesh, small to large pieces } \\
\text { and occasional blocks (totalling < 1000 kg) of rock dislodged } \\
\text { Moderate new bagging of mesh by fractured and displaced rock } \\
\text { Clear evidence of newly fractured rock, possibly displaced violently }\end{array}$ \\
\hline R4 & $\begin{array}{l}\text { Moderate to } \\
\text { considerable damage } \\
\text { to excavations } \\
\text { Violent displacement } \\
\text { of 'loose' and freshly } \\
\text { broken rock }\end{array}$ & $\begin{array}{l}\text { Unsupported drifts sustain damage at multiple locations } \\
\text { Drifts supported with only rockbolts and mesh are damaged with } \\
\text { substantial rock displaced (<10000 kg) but are still passable } \\
\text { Rock is heavily fractured and displaced violently }\end{array}$ \\
\hline $\begin{array}{l}\text { Serious or severe } \\
\text { damage to excavations } \\
\text { Opening collapsed }\end{array}$ & $\begin{array}{l}\text { Unsupported drifts completely closed } \\
\text { Drifts supported with only rockbolts and mesh heavily damaged and } \\
\text { unpassable } \\
\text { Substantial amounts of rock displaced (> 10000 kg) } \\
\text { Rock is highly broken and fractured }\end{array}$ \\
\hline
\end{tabular}

Figure 5 Rock mass damage scale (Kaiser et al. 1995)

\subsubsection{Support damage}

It is important to capture the location in the profile (shoulders, backs, walls) of the damage, so that trends can be identified in back-analysis. Having the orientation of these (i.e. north wall, south shoulder) can further help to identify trends that may be due to local geological or stress conditions.

Kaiser et al. (1995) also proposed support and shotcrete damage scales, which are useful to capture. Mikula \& Gebremedhin (2017) proposed a simplified support damage scale, consisting of just three levels of damage (acceptable, tolerable and intolerable) corresponding to S0-1, S2-3 and S4-5 respectively. This is a practical scale to use because it helps to categorise damage by the level of rehabilitation required. 
More-detailed damage information can be collected on individual support elements, as shown in Table 5.

Table 5 Detailed ground support element damage information

\begin{tabular}{llll}
\hline Bolt & Mesh & Straps & Shotcrete \\
\hline Type of bolt damaged & Type of mesh damaged & Type of strap damaged & $\begin{array}{l}\text { Type of shotcrete } \\
\text { damaged }\end{array}$ \\
$\begin{array}{l}\text { Number of damaged } \\
\text { bolts }\end{array}$ & $\begin{array}{l}\text { Bagging/displacement } \\
\text { between bolts }\end{array}$ & $\begin{array}{l}\text { Bagging/displacement } \\
\text { between bolts }\end{array}$ & $\begin{array}{l}\text { Extent of cracking } \\
\text { Failure mechanism }\end{array}$ \\
$\begin{array}{l}\text { Mesh damage } \\
\text { mechanism }\end{array}$ & $\begin{array}{l}\text { Strap damage } \\
\text { mechanism }\end{array}$ & $\begin{array}{l}\text { Average width of } \\
\text { cracking }\end{array}$ \\
Plate deflection & & & \\
\hline
\end{tabular}

\subsection{Other information}

Having the ability to write free-form notes is important, as it allows the user to add any additional information that is not catered for in the predefined database form.

Photos are also of critical importance, as they allow for proper documentation and more qualitative analysis of damage occurrences. When collecting and storing photos, they should be connected to a specific location underground and stored in a systematic manner. This allows for easy access to the photos and can allow simple comparison of changes to a location over time.

\section{$4 \quad$ Application design}

The application design had to satisfy four main criteria:

- Simple, user-friendly interface.

- High data-input speed.

- Comprehensive data capture into a logical database structure.

- Where possible, standardised and consistent inputs.

\subsection{Hardware}

The application was designed to work with tablet devices. This would allow easy digital input while underground, thus creating a single-pass system. The data collection system was to be web browser based, as this would not require installation of any software (other than a suitable browser). This would also remove the need to create an app on three separate app stores, given that the tablets used on site can be Windows, iOS or Android devices. The web form was designed to be cached so that it could be accessed offline, as many mine sites do not have access to a wireless network underground. The data is synchronised to and from a simple Java server hosted by a computer on the mine network. More details about the server are given in Section 4.4.

\subsection{Layout and input}

The data input was designed as a form, with the different input fields sorted under headings. Each heading has a small button adjacent to it, which the user taps/clicks to open the field inputs for that heading. The heading buttons have three states: red, for when no data has been entered in any of the fields; yellow, for when data has been entered in some of the fields; and green, for when all the required data have been entered for that heading. This allows the user to see at a glance which sections require data input. The different states for the heading buttons can be seen in Figure 6 . 


\title{
Installed Ground Support
}

\author{
Installed Ground Support
}

政

Installed Ground Support

Figure 6 States for heading buttons

The majority of the fields were given a drop-down style of input (Figure 7a). This was to achieve the requirement of consistency within the database and for ease/speed of input. For the observation date and time, a specific date/time input was used (Figure $7 \mathrm{~b}$ ). For some number fields, a simple number input was used (Figure 7c), and for fields requiring free-form text, a simple text input was used (Figure 7d).

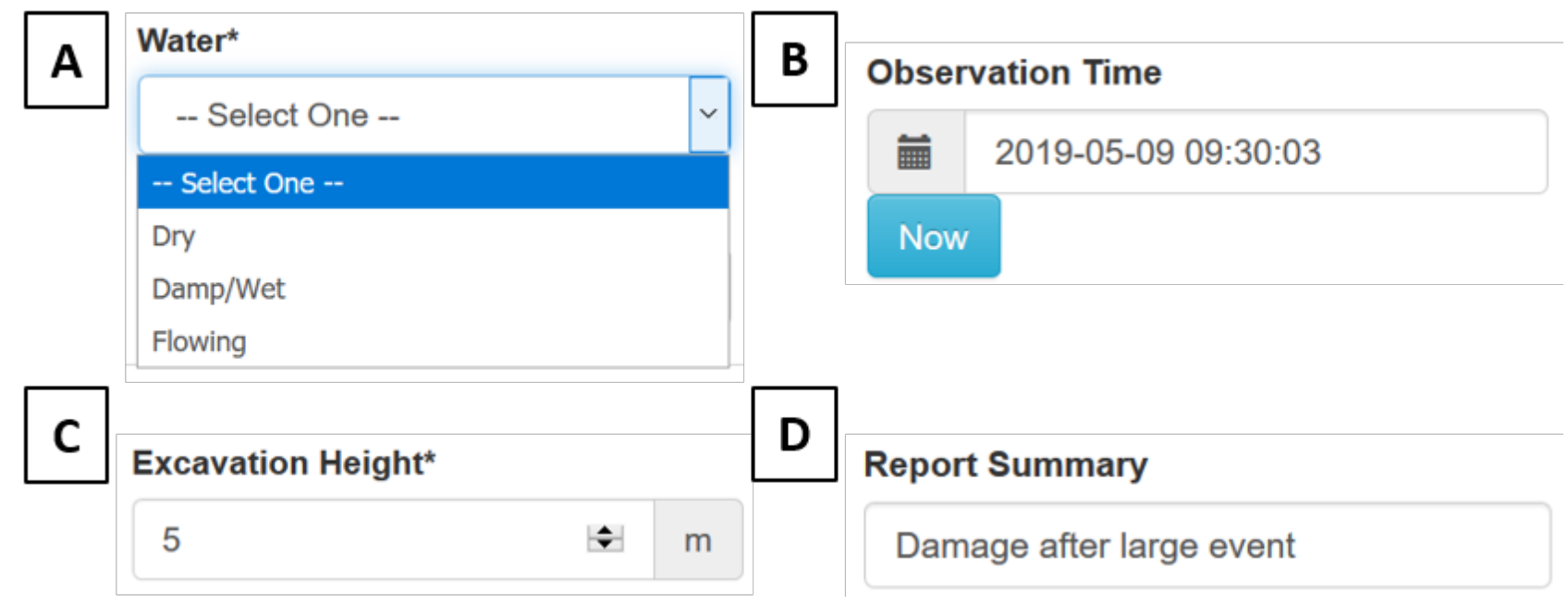

Figure 7 Example input types: (a) Drop-down, (b) Date/time, (c) Number, and (d) Text

\subsubsection{Track selection and editing}

The web form has a map, which shows a level plan including excavation solids or floor strings, along with the existing tracks on that level. There are two modes to the map: the track selector and the track editor. The track selector shows all current tracks, and the user can select which tracks will be part of the report. The track editor allows the user to add new tracks and edit existing tracks. Tracks are moved by use of the mouse (or finger when using a tablet), with a 'click-and-hold' function. Custom controls were created to edit track rotation, width and length. They can be changed by directly typing in a value or using a scroll bar or using buttons (large adjustment or fine adjustment). Tracks can also be deleted or changed to a different type (e.g. a 3-way intersection can be changed to a 4-way intersection). An example of the track editing controls is shown in Figure 8. 


\section{Editing Track}

Move (or drag the selected track on the map):

Show Move Buttons

Rotate:
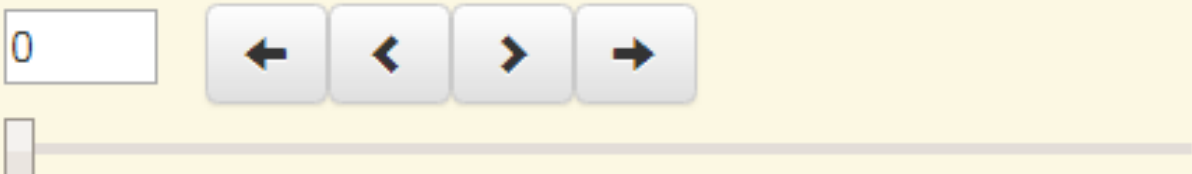

Width:
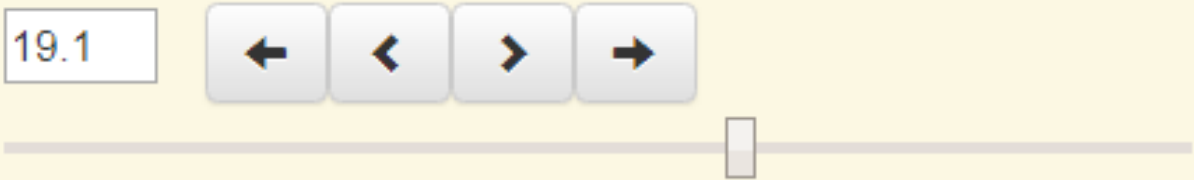

Length:

\section{1}

Delete

Position: 15699.47, 22090.28

\section{Cancel}

\section{Change Track Type}

\section{Figure 8 Example of track editing controls}

\subsubsection{Structural-data input}

A custom input widget was created for input of structural data (foliation and major structures). The input shows the track (correctly oriented), along with an overlay of the foliation/major structure. The user can move the foliation/major structure around by either changing the dip and dip direction fields directly or by using a scroll bar underneath. The user can also adjust the values by increments of 1 or 10 using buttons. This allows the user to easily input approximate orientations of structural data and allows them to input direct measurements (i.e. from a compass). An example of the structural input for foliation is given in Figure 9. 


\section{Foliation (relative to North)}

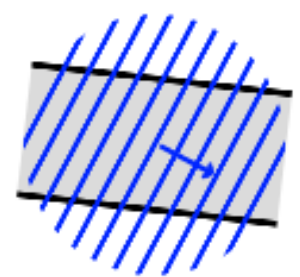

$$
\uparrow_{N}^{A}
$$

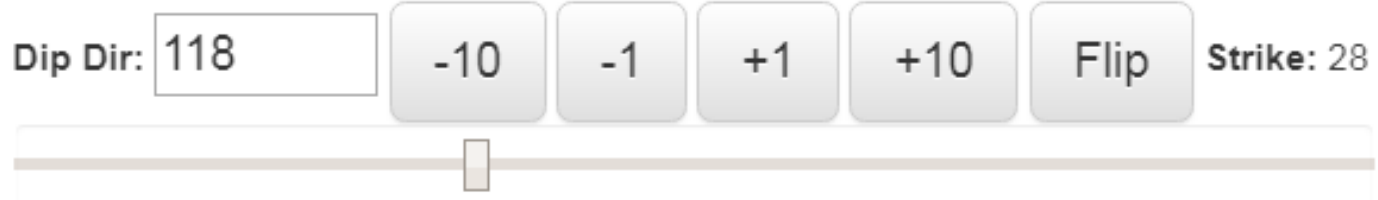

Dip: $31+-10+10+10$

\section{Figure 9 Example of structural input for foliation}

\subsubsection{Installed-support input}

The custom input widget for installed support allows the user to select the support types used, along with the relevant information (bolt spacing, thickness of shotcrete, etc.). This selection can then be assigned to the relevant points on the profile by the user (Figure 10).

\begin{tabular}{|l|l|l|l|l|}
\hline Rosin Bolt \\
Bing Spacing* \\
\hline $1.2 \mathrm{~m}$
\end{tabular}

Figure 10 Example of installed-support input 
Mines can also save their ground support profiles/standards to allow for event faster input. Once the profile has been saved, the user can choose it from the list and the chosen support will be automatically applied. This simple input can help mines to easily build a digital record of installed support for their mine-something many mines do not have.

\subsubsection{Fall-of-ground input}

Falls of ground require an input similar to that of the installed ground support. The details for the fall of ground are entered (size, fragmentation, etc.), and then the fall of ground is assigned to points on the profile. In the example shown in Figure 11, the fall of ground is assigned to the backs and the right shoulder. Multiple falls of ground can be input per track (e.g. a fall of ground from the right wall and another from the left).

\section{Assignment*}
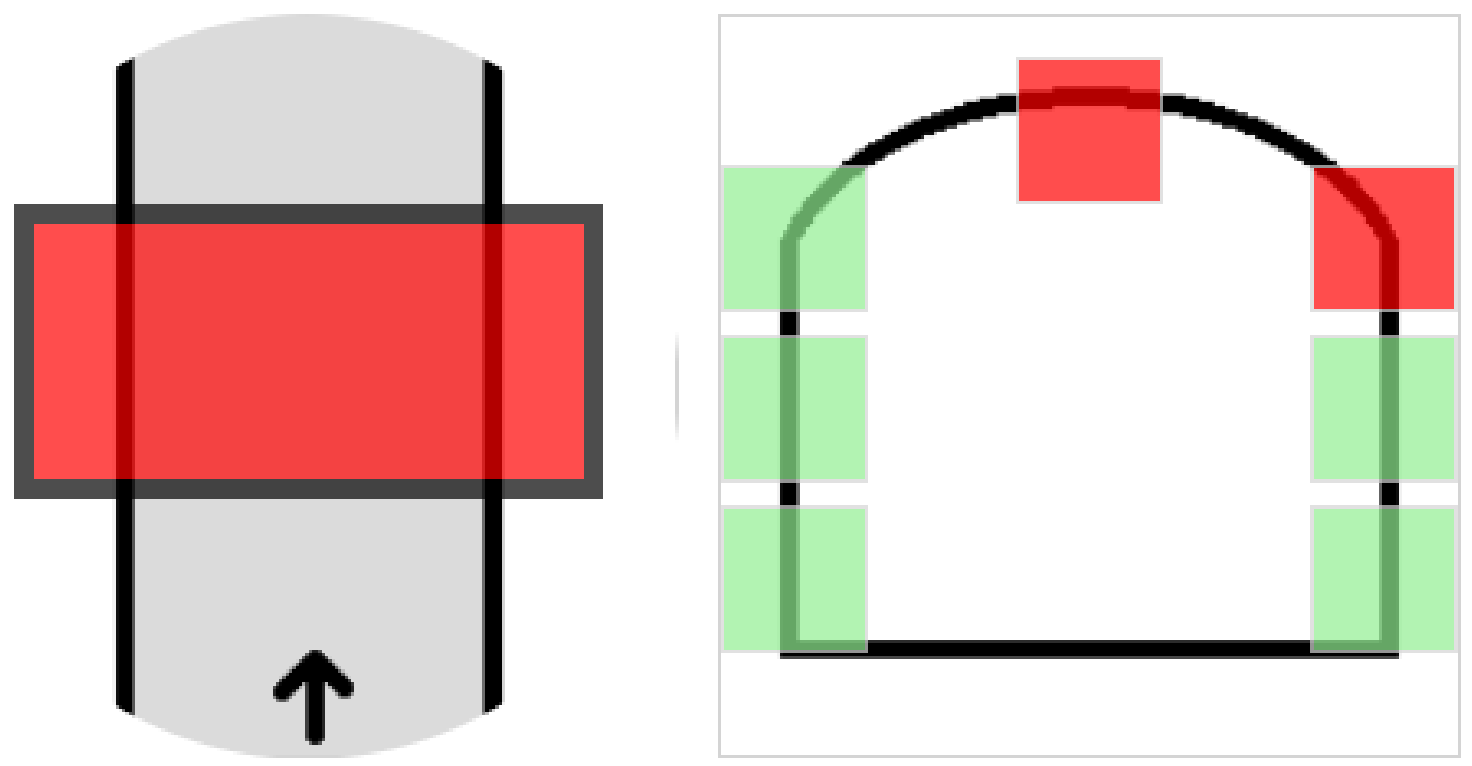

Figure 11 Example of fall-of-ground input

\subsubsection{Photo input}

A photo input button allows the user to attach photos to any of the three levels (report, track and point). This allows users to easily link photos to locations underground and thus track damage in these locations over time. On Windows devices, the input allows the user to browse to image files. On Android and iOS devices, the user is prompted to either select a file from the device or open the camera app to take a photo, which is automatically attached.

\subsubsection{Copying data}

There are many cases where the input fields do not vary between tracks or between points. In these cases, there is a significant time-saving benefit to being able to copy the data between tracks/points. The data copy buttons are separated into track and point data in order to prevent inadvertent copying of damage data. Some fields (such as falls of ground) are not copied, as they are unlikely to be identical in two separate locations. 


\subsubsection{Past data}

The web form has a button at the top of each section to allow users to see the previous report's data for that section (Figure 12). There is also a button allowing the user to copy in this previous data, accelerating input in cases where there is little to no change in damage. The ability to query the previous status of the development also allows 'fresh' damage or change to be identified.

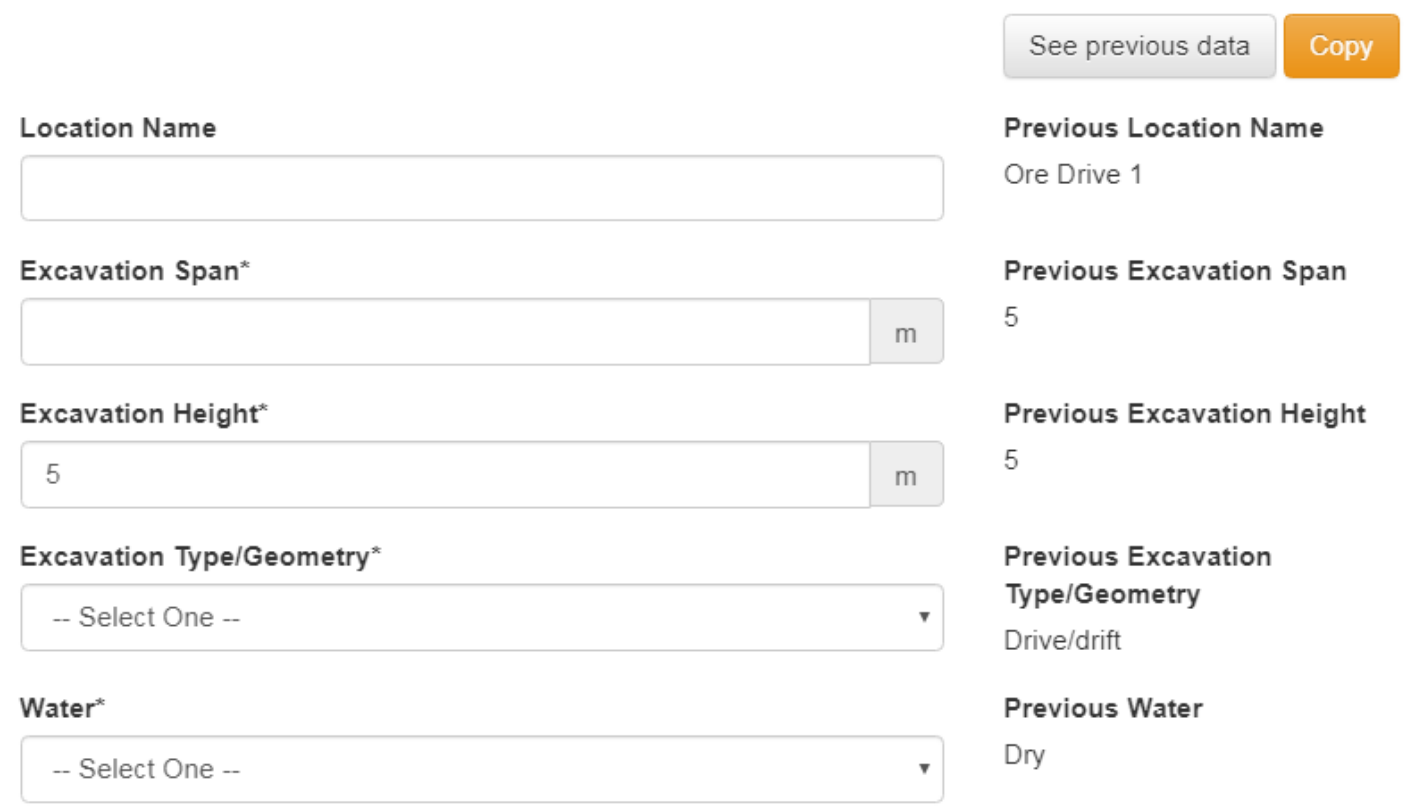

Figure 12 Previous data view and copy buttons

\subsubsection{Form logic}

Using form logic is crucial to ensure database integrity and improve speed of input. Some fields are only relevant if there is a specific answer to another field (e.g. if there is no fall of ground, the depth of failure cannot usually be evaluated). Some fields need to be limited based on the answers from previous fields (e.g. the corrosion field is only relevant for the support elements installed).

\subsection{Site customisation}

A number of sites using the application gave feedback indicating that they wanted to use the app for ground support installed quality control and routine damage mapping (i.e. everyday inspections). In order to cater for this, site customisation was added. Specific report types can be customised by adding fields or by hiding fields to achieve the style of report that works best for each individual site.

\subsection{Server details}

The system is set up so that the custom-built Java web server (hosted on the mine network) serves a static page to the tablet device. Once the user has input data, the data is placed in a queue for submission. If the tablet is offline, the queue is executed when the tablet is re-connected to the network. The server receives the input data and writes it as files on the mine network disk. These files are read and processed in $m$ Xrap (Harris \& Wesseloo 2015). The data for the web pages is then transferred to the server so that it can serve pages with updated data. A schematic of data flow is given in Figure 13. 


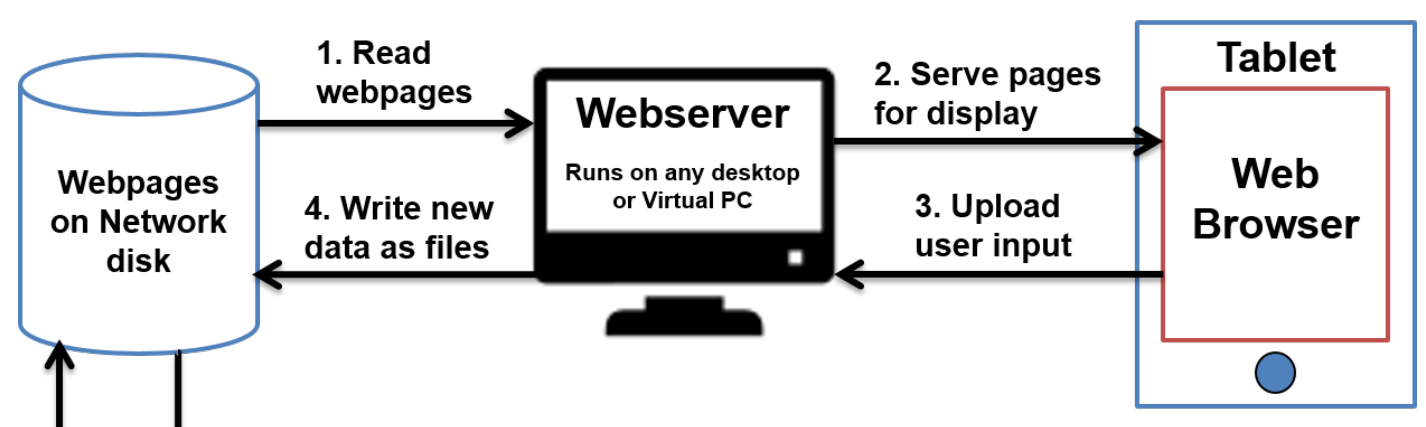

Figure 13 Schematic of data flow

\section{$5 \quad$ Integration into $\mathrm{mXrap}$}

Once the data from the web form has been synchronised to the server, it can be accessed through the mXrap software package. All of the data (including photos, installed ground support, etc.) can be analysed in mXrap, along with other mine data (seismic events, blasts, etc.). An example of this is given in Figure 14. Users can also create a schedule in $\mathrm{mXrap}$, requiring certain tracks to be inspected at regular intervals.

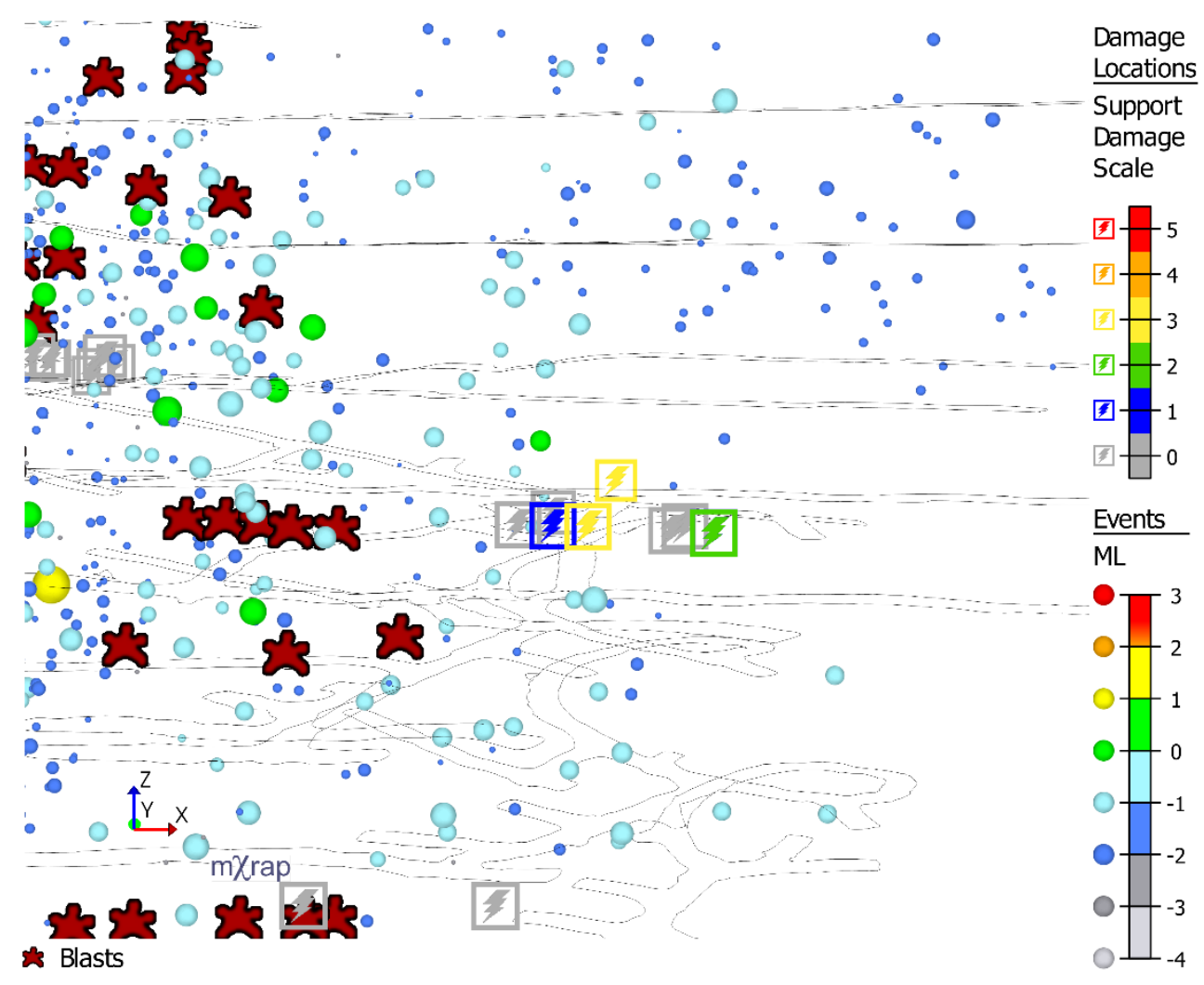

Figure 14 Example of data visualisation in mXrap 


\section{Concluding remarks}

A damage mapping application for tablet devices was designed and created as part of the Australian Centre for Geomechanics' GSSO2 project. The app achieved its primary goals of ease of use, rapid and comprehensive damage mapping data input through deliberate design and use of custom input widgets. Offline caching allows for a single-pass system, with data being captured digitally and easily available for analysis in mXrap. Compared with the industry standard (manual pen and paper mapping), the application should not only save time for geotechnical engineers but also create consistent high-quality data that can be used in back-analysis.

\section{Acknowledgement}

The authors acknowledge the sponsors of the Ground Support Systems Optimisation Phase 2 Project. Industry sponsors: Agnico Eagle Mines Limited, BHP Base Metals, IAMGOLD Corporation, Independence Group NL, Gold Fields Australia and Newcrest Mining Limited. Government sponsors: Minerals Research Institute of Western Australia. Supplier Sponsors: DSI Underground, Fero Strata Australia, Garock, Jennmar, New Concept Mining and Sandvik.

We also acknowledge the mXrap Consortium for help with developing the application and server functionality.

\section{References}

Duan, W, Wesseloo, J \& Potvin, Y 2015, 'Evaluation of the adjusted rockburst damage potential method for dynamic ground support selection in extreme rockburst conditions', in Y Potvin (ed.), Proceedings of the International Seminar on Design Methods in Underground Mining, Australian Centre for Geomechanics, Perth, pp. 399-418.

Harris, PC \& Wesseloo, J 2015, mXrap, version 5.9, computer software, Australian Centre for Geomechanics, Perth, https://www.mxrap.com

Kaiser, PK, McCreath, DR \& Tannant, DD 1995, Canadian Rockburst Support Handbook, Geomechanics Research Centre, Laurentian University, Sudbury.

Mikula, P \& Gebremedhin, B 2017, 'Empirical selection of ground support for dynamic conditions using charting of support performance at Hamlet mine', in J Wesseloo (ed.), Proceedings of the Eighth International Conference on Deep and High Stress Mining, Australian Centre for Geomechanics, Perth, pp. 625-636. 
